\title{
Identification of T-cell epitopes in Francisella tularensis using an ordered protein array of serological targets
}

Michael D. Valentino, ${ }^{1}$ Zachary J. Maben, ${ }^{1}$ Lucinda L. Hensley, ${ }^{2}$ Matthew D. Woolard, ${ }^{2,3}$ Thomas H. Kawula, ${ }^{2}$ Jeffrey A. Frelinger ${ }^{2,4}$ and John G. Frelinger ${ }^{1}$

${ }^{1}$ Department of Microbiology and Immunology, University of Rochester School of Medicine and Dentistry, Rochester, NY, ${ }^{2}$ Department of Microbiology and Immunology, University of North Carolina at Chapel Hill, Chapel Hill, NC, ${ }^{3}$ Department of Microbiology and Immunology, Louisiana State University Health Science Center at Shreveport, Shreveport, LA, and ${ }^{4}$ Department of Immunobiology, University of Arizona, Tucson, AZ, USA

doi:10.1111/j.1365-2567.2010.03387.x Received 17 September 2010; revised 11 November 2010; accepted 12 November 2010.

Correspondence: Dr M. D. Valentino, Department of Microbiology and Immunology, University of Rochester School of Medicine and Dentistry, 601 Elmwood Avenue Box 672, Rochester, NY 14642, USA. Email:michael_valentino@urmc.rochester.edu Senior author: John G. Frelinger, email: jfrelinger@gmail.com

\begin{abstract}
Summary
Francisella tularensis is a Gram-negative intracellular bacterium that is the causative agent of tularaemia. Concerns regarding its use as a bioterrorism agent have led to a renewed interest in the biology of infection, host response and pathogenesis. A robust T-cell response is critical to confer protection against $F$. tularensis. However, characterization of the cellular immune response has been hindered by the paucity of tools to examine the anti-Francisella immune response at the molecular level. We set out to combine recent advances of genomics with solid-phase antigen delivery coupled with a T-cell functional assay to identify T-cell epitopes. A subset of clones, encoding serological targets, was selected from an $F$. tularensis SchuS4 ordered genomic library and subcloned into a bacterial expression vector to test the feasibility of this approach. Proteins were expressed and purified individually employing the BioRobot 3000 in a semi-automated purification method. The purified proteins were coupled to beads, delivered to antigen-presenting cells for processing, and screened with Francisella-specific T-cell hybridomas of unknown specificity. We identified cellular reactivity against the pathogenicity protein IglB, and the chaperone proteins GroEL and DnaK. Further analyses using genetic deletions and synthetic peptides were performed to identify the minimal peptide epitopes. Priming with the peptide epitopes before infection with $F$. tularensis LVS increased the frequency of antigen-specific CD4 T cells as assessed by intracellular interferon- $\gamma$ staining. These results illustrate the feasibility of screening an arrayed protein library that should be applicable to a variety of pathogens.
\end{abstract}

Keywords: epitope discovery; Francisella tularensis; gateway genomic array; proteomic array; $\mathrm{T}$ lymphocyte

\section{Introduction}

Francisella tularensis is a Gram-negative intracellular bacterium that is the causative agent of tularaemia. It can be found naturally occurring in the environment, infecting a variety of mammals including mice, squirrels and rabbits. Transmission to humans can occur through direct contact with infected animals, ingestion or inhalation of organisms, or via arthropod bites. ${ }^{1}$ Because of the severity of tularaemia, the low infectious dose, and its past use as a biological agent, $F$. tularensis has been classified as a Cate- gory A Select Agent (http://www.cdc.gov). ${ }^{2}$ The recent concerns regarding the possible use of these organisms as a bioterrorism agent has led to a renewed interest in understanding the biology of infection, pathogenesis, and the host response to F. tularensis.

Francisella has been classified into several closely related species. The subspecies primarily associated with human disease are F. tularensis subsp. tularensis and F. tularensis subsp. holarctica. The F. tularensis subsp. tularensis, also referred to as Type A, is found primarily in North America, whereas the F. tularensis subsp. holarctica, also called

Abbreviations: $6 \times$ His, $6 \times$ histidine tag; APC, antigen-presenting cell; DHFR, dihydrofolate reductase; LVS, live vaccine strain; ORF, open reading frame; STS, serological target subset; THIO, thioredoxin. 
Type B, can be found throughout Europe, as well as in North America. Francisella Type A strains in general cause a more severe illness in humans than the Type B strains. ${ }^{3}$ The SchuS4 strain of F. tularensis subsp. tularensis and the F. tularensis subsp. holarctica derivative known as the Live Vaccine Strain (LVS), which has been attenuated in humans by serial passage through animals, are two of the best characterized Francisella strains. Although there are no licensed vaccines for F. tularensis in the United States, the attenuated Type B strain LVS has been used as a vaccine in Europe and is widely used in experimental animal studies. ${ }^{4-6}$ Francisella novicida (which has also been referred as F. tularensis subsp. novicida) is primarily an animal pathogen that does not generally cause disease in humans. ${ }^{7}$ Although Francisella exhibits different levels of virulence in humans that is strain dependent, all strains retain a high level of virulence in mice. ${ }^{6}$ Interestingly, genomic studies revealed a high degree of sequence identity among the various species (>95\%) although these analyses also revealed a considerable number of gene duplications, deletions and rearrangements. ${ }^{8,9}$

The immune response to F. tularensis is of particular interest given this bacterium's potential use as a biological weapon. Mice inoculated with F. tularensis exhibit many similarities to infected humans and have often been used as a model for the host immune response to F. tularensis. ${ }^{6,10}$ As might be expected for an organism that can grow inside mammalian cells, studies have revealed that $\mathrm{T}$ cells are major contributors to clearance and immunity. ${ }^{5}$ The virulence of F. tularensis may be partly related to a weak initial innate response to live Francisella organisms, as well as to active suppression of $\mathrm{T}$ cells, resulting in a compromised cell-mediated response. ${ }^{11-17} \mathrm{CD}^{+}, \mathrm{CD}^{+}$and $\mathrm{T}$ helper type $17 \mathrm{~T}$ cells both contribute to clearance and immunity. ${ }^{18-23}$ In addition, another unusual T-cell subset (i.e. $\mathrm{TCR}^{+}$, $\mathrm{CD}^{-}, \mathrm{CD}^{-}, \mathrm{NK} 1.1^{-}$) can also contribute to the cellular response to F. tularensis. ${ }^{24-27}$ Interestingly, a role for antibodies and $\mathrm{B}$ cells has been implicated in protective immunity, illustrating additional complexity of the immune response to F. tularensis. ${ }^{28-31}$ Recent studies have shed considerable light regarding the immune response to this organism, when compared with other intracellular organisms such as Mycobacterium or Listeria, the immune response is relatively poorly understood.

Characterization of the cell-mediated immune response to F. tularensis has been hampered by the lack of tools to examine and measure the immune response at the molecular level. The identification of specific T-cell epitopes would greatly aid in the ability to measure and characterize the host immune response. We have previously developed a method to identify T-cell epitopes using T-cell hybridomas combined with antigens coupled to beads delivered to antigen-presenting cells (APC). ${ }^{32}$ Using this approach we were able to identify an immunodominant epitope of the Tul4 (also referred to as LpnA) lipoprotein in F. tularensis. ${ }^{33}$ We set out to extend this approach and develop methods that could be used to identify T-cell epitopes using an arrayed genomic library of $F$. tularensis SchuS4. To test this approach, a selected subset of 45 clones was chosen and subcloned into a bacterial expression vector pBAD-DEST49 using the Gateway system. The majority of these clones were selected based upon their previous identification as serological targets of the immune response against Francisella, ${ }^{34-37}$ which we could use to validate their recombinant expression and might also be expected to include T-cell epitopes. These clones were then used to express $6 \times$ His-tagged proteins that were purified using a semi-automated procedure (Qiagen Biorobot 3000), subsequently coupled to beads, and screened using a panel of T-cell hybridomas generated against F. tularensis LVS to identify T-cell epitopes. The results illustrate that this methodology should also be applicable to large-scale screening of F. tularensis and would also be generally applicable to other organisms.

\section{Materials and methods}

\section{Mice, cell lines and bacteria}

All animal experiments were performed in accordance with guidelines established by the National Institutes of Health and the University Committee on Animal Resources at the University of Rochester or the University of North Carolina. C57BL/6 $\left(\mathrm{H}^{b}\right)$ mice were purchased from the Jackson Laboratory (Bar Harbor, ME). The T-cell fusion partner BWZ.36/CD8 ${ }^{+}$was kindly provided by Dr Nilabh Shastri and maintained as previously described. ${ }^{38}$ Francisella tularensis lysates were generated from Live Vaccine Strain (LVS) obtained from the CDC (Atlanta, GA) and SchuS4 from BEI Resources (Manassas, VA). The F. novicida U112 and the F. novicida U112 transposon mutant library were gifts from Dr Colin Manoil. ${ }^{39}$ Bacteria were grown on chocolate agar and viability was quantified by serial dilution.

\section{Thioredoxin and dihydrofolate reductase fusion protein constructs}

A genomic library containing the majority of the F. tularensis SchuS4 open reading frames (ORFs) was obtained from The Venter Institute in an arrayed format of pDONR221 clones. The 45 thioredoxin (THIO) fusion proteins from the Serologic Target Subset (STS) array were produced by shuttling the selected $F$. tularensis gene from the pDONR221 entry vector (J. Craig Venter Institute, San Diego, CA) into the bacterial expression vector pBAD-DEST49 using the Gateway Cloning technology (Invitrogen, Carlsbad, CA) following the manufacturer's protocol. The expression vector pBAD-DEST49 creates a fusion protein containing the bacterial protein THIO 
fused in frame with an individual ORF from F. tularensis SchuS4 followed by V5 and $6 \times$ histidine $(6 \times$ His) coding regions. Subgenomic constructs used for mapping experiments were generated by PCR amplification from the appropriate pDONR221 entry clone DNA. Immunoglobulin $\mathrm{lB}$ deletion constructs were generated with a $3^{\prime}$ primer that began at the first base pair of the start methionine codon and a set of $5^{\prime}$ primers to amplify gene regions corresponding to $1-1170,1-1341,1-957,1-666,1-585$ and $1-315 \mathrm{bp}$. Additional IglB deletion constructs were generated by the primer sets corresponding to: 1158$1299,1278-1413$ and $1362-1542$ bp. In a similar fashion, gene regions in GroEL were produced: 1080-1323, 12271476 and 1440-1542 bp; as well as gene regions in DnaK: 1-303, 270-531, 327-531 and 1-366 bp. The PCR products were then cloned into the pCR8/GW/TOPO vector using the TOPO cloning kit (Invitrogen) following the manufacturer's protocol, generating an entry vector that can then be shuttled to the pBAD-DEST49 vector using the Gateway Cloning technology as described above. All proteins produced from pBAD-DEST49 vector will be designated THIO-(protein) because they are generated as fusion proteins with thioredoxin.

All dihydrofolate reductase (DHFR) fusion proteins were generated using the bacterial expression vector pQE40, which contains a $6 \times$ His followed by the murine protein DHFR, as described in Valentino et al. ${ }^{33}$ Briefly, gene fragments were amplified from $F$. tularensis LVS genomic DNA using PCR primers specific for: groEL 1-597, 513-1143 and 1080-1323 bp; or dnaK 1-531, 4771002, 945-1515 and 1449-1929 bp. Amplified PCR products were cloned into the $\mathrm{PQE} 40$ vector using restriction sites designed into the primers and standard molecular techniques. All proteins produced from pQE40 vector will be designated DHFR-(protein) because they are generated as fusion proteins with DHFR.

\section{Recombinant protein production}

Production of THIO fusion proteins were performed in Escherichia coli strain TOP10 as described by manufacturer's specifications (Invitrogen). Production of DHFR fusion proteins were performed in E. coli strain M15 (Qiagen, Valencia, CA) as previously described. ${ }^{33}$ Protein expression was induced in bacteria containing pBADDEST49 (THIO) and pQE40 (DHFR) using L-arabinose and isopropyl beta-D-1-thiogalactopyranoside, respectively, with an absorbance at optical density at $600 \mathrm{~nm}$ of $0 \cdot 6-1 \cdot 0$. Recombinant proteins were isolated by lysing the bacterial pellets with $8 \mathrm{~m}$ urea $(\mathrm{pH} \mathrm{8.0)}$ ) and purified over an Ni-NTA column (Qiagen) in high-throughput fashion using a BioRobot 3000 (Qiagen) as described in Valentino and Frelinger. ${ }^{40}$ Protein was coupled to tosyl-activated M280 magnetic Dynabeads (Invitrogen) as follows: $1 \times 10^{7}$ beads with $8 \mu \mathrm{g}$ recombinant fusion protein were mixed overnight at $37^{\circ}$ in $0 \cdot 1 \mathrm{M}$ borate buffer, washed three times with PBS using magnetic separation, and diluted to working volume in PBS $\left(2 \times 10^{5}\right.$ beads $\left./ \mathrm{ml}\right)$. Coupling the arrayed STS proteins to beads was carried out as described above in a $1.2 \mathrm{ml}$ deep 96-well plate. All deletion proteins were characterized by SDS-PAGE and either stained with Coomassie Blue or transferred to Hybond $\mathrm{C}$ mixed ester nitrocellulose membrane (GE Healthcare Life Sciences, Piscataway, NJ) and analysed by Western blotting techniques ${ }^{32}$ (data not shown), followed by primary antibody anti-THIO (Invitrogen) (1:5000) or anti-V5 (Invitrogen) (1: 5000), secondary antibody rabbit anti-mouse IgG conjugated to horseradish peroxidase (Jackson ImmunoResearch Labs, West Grove, PA), and detection by $\mathrm{ECL}^{+}$chemiluminescent reagent (GE Healthcare Life Sciences).

Generation of Francisella anti-sera and immunoblotting

Anti-sera from C57BL/6 mice that were infected intradermally with $10^{5}$ colony-forming units of F. tularensis LVS and boosted intraperitoneally 6 weeks later with a 50\% lethal dose of 100 before harvesting blood was provided by Dr Mingtao Zeng. The Adeno-Tul4 sera, generously provided by Dr Steven Dewhurst, was generated by immunizing C57BL/6 mice by tail vein injection with $10^{6}$ colony-forming units of adenoviral vector expressing Tul4 followed by a homologous boost before harvesting sera. After purification, an aliquot of each protein in the STS array was blotted onto Hybond C membrane using a 96-well dot blot apparatus following the manufacturer's specifications (Bio-Rad, Hercules, CA). The membrane was blocked with 5\% non-fat dry milk in TBS-Tween before probing with either anti-sera from tularaemic infection at $1: 300$ dilution, Adeno-Tul4 sera at $1: 300$ dilution, anti-THIO antibody at $1: 5000$ dilution, or anti-V5 antibody at 1:5000 dilution for $2 \mathrm{hr}$ at room temperature. The membrane was then washed three times in TBS-Tween before addition of rabbit anti-mouse IgG conjugated to horseradish peroxidase detection antibody at a $1: 5000$ dilution for $1 \mathrm{hr}$ at room temperature, followed by washing and detection using the $\mathrm{ECL}^{+}$chemiluminescent reagent (GE Healthcare Life Sciences).

\section{Generation of T-cell hybridomas}

The T-cell hybridomas were produced as described in Valentino et al. ${ }^{33}$ Briefly, hybridomas were generated by intradermal injection into C57BL/6 mice at the base of the tail with heat-killed bacteria or $1 \times 10^{5}$ viable $F$. tularensis $\mathrm{LVS}^{4}$ and allowing the animals to resolve the infection before harvesting splenocytes. Following several rounds of in vitro restimulation, the $\mathrm{T}$-cell blasts were fused with the BWZ.36/CD8 ${ }^{+}$fusion partner containing lacZ driven by the Interleukin-2 promotor element as described previously. $^{32,38}$ Fusions were grown in hypoxanthine- 
aminopterin-thymidine selection media until clones could be evaluated for activity, measured by a $\beta$-galactosidase substrate in 96 -well plates as previously described. ${ }^{32}$

\section{Antigen presentation assays}

The antigen presentation assay was adapted from the T-cell antigen discovery assay. ${ }^{32}$ Presentation assays were performed by incubating $1 \times 10^{5}$ hybridomas with $5 \times 10^{5}$ APCs in $200 \mu \mathrm{l}$ total volume per well in a 96-well tissue culture plate. The APCs were splenocytes isolated from naive wild-type C57BL/6 mice. All recombinant proteins isolated from bacterial lysates were conjugated to tosyl-activated beads as described above and used at $2 \times 10^{6}$ beads per well. Assays were also performed in $200-\mu \mathrm{l}$ volumes in the presence of the synthesized peptides listed below at $10 \mu \mathrm{g}$ per peptide per well (SynBioSci, Livermore, CA or RS Synthesis, Louisville, KY) and Francisella lysates at $20 \mu \mathrm{g}$ per well. Francisella extracts were produced by killing F. tularensis LVS, SchuS4, or F. novicida in $70 \%$ ethanol overnight at $-20^{\circ}$ followed by pelleting and resuspension in PBS. ${ }^{11}$ Plate bound antiCD3 (clone 500A2) (BD Pharmingen, San Jose, CA) was also included in each assay (not shown in figures) as a positive control for hybridoma viability and functionality. After $18-24 \mathrm{hr}$ incubation at $37^{\circ}$, cultures were developed using the $\beta$-galactosidase assay. The hybridomas contain a reporter gene system in which activated $\mathrm{T}$ cells express $\beta$-galactosidase. ${ }^{32,38}$ For data analysis, activated cells were enumerated as described previously. ${ }^{33}$

\section{In silico peptide prediction}

The refined regions shown by deletion protein mapping to contain an epitope were analysed with several peptide prediction algorithms: Rankpep, http://imed.med.ucm.es/ Tools/rankpep.html; NetMHCII 2.0, http://www.cbs.dtu. $\mathrm{dk} /$ services/NetMHCII-2.0/; and IEDB Analysis Resource using consensus, arbpython, and smm-align prediction methods http://tools.immuneepitope.org/analyze/html/ mhc_II_binding.html. The entire amino acid sequences for IglB, GroEL and DnaK proteins were also retrospectively analysed for peptide binders using the prediction algorithms listed above, as mentioned in the Discussion.

\section{Synthetic peptides}

All synthetic IglB and GroEL peptides were synthesized by SynBioSci and are as follows: IglB 472-486 (IPGKPGWYSCKINVI), IglB 475-489 (KPGWYSCKINVIPHI), IglB 475-486 (KPGWYSCKINVI), GroEL 441-455 (ALLRKAIEAPLRQIV), and GroEL 463-477 (SVVVNQVKAN QGNYG). The peptide DnaK 109-122 (GKKMAPPQVSAEVL) was synthesized by RS Synthesis. The Tul4 86-99 (RLQWQAPEGSKCHD) peptide derived from F. tularen- sis was also synthesized by SynBioSci. ${ }^{33}$ Ovalbumin (OVA) 323-339 (pOVAII) peptide (ISQAVHAAHAEINEAGR) served as an irrelevant peptide negative control and was synthesized by Macro-Molecular Resources (University of Colorado, Fort Collins, CO).

\section{Analysis of in vivo epitope frequency}

Analysis of in vivo immunogenicity was performed on the whole as described previously. ${ }^{20,33}$ In brief, cohorts of C57BL/6 mice were treated with one of the following three experimental protocols: (i) peptide immunization followed by sham infection; (ii) sham immunization followed by F. tularensis LVS infection; or (iii) peptide immunization followed by $F$. tularensis LVS infection. Mice that received peptide immunization were injected in the footpad with a mixture of IglB 475-489, GroEL 466480 and DnaK 109-122 peptides (35 $\mu$ g each) emulsified in complete Freund's adjuvant (CFA) or PBS in CFA. Mice that were infected were inoculated with $1 \times 10^{5}$ colony-forming units of $F$. tularensis LVS intradermally at the base of the tail. Sham immunization or infection was performed with PBS at matched anatomical locations. All mice were rested for 3 weeks following peptide or sham immunization and harvested 10 days after F. tularensis LVS or sham infection. Splenocytes from all three treatments were stimulated for 18-24 hr in vitro with $100 \mu \mathrm{g} /$ $\mathrm{ml}$ ethanol-killed F. tularensis LVS extract (FT Ag), IglB 475-489 peptide, GroEL 466-480 peptide, DnaK 109-122 peptide or an irrelevant MHC class II OVA 323-339 peptide. Brefeldin A was added to the incubations for the last $4 \mathrm{hr}$. Cells were then washed and surface stained with anti-CD19 PE-Cy7 (BD Pharmingen; clone 1D3), antiCD11c PE-Texas Red (Invitrogen; clone N418), antiCD11b APC750 (eBiosciences, San Diego, CA; clone M1/ 70), anti-TCRab Alexa488 (Biolegend, San Diego, CA; clone H57-597), anti-CD3 APC (eBiosciences; clone 1452C11) and anti-CD4 PacBlue (Invitrogen, clone; RM4-5). The cells were fixed and permeablized using eBioscience reagents and protocols (eBioscience), then stained with anti-IFN- $\gamma$ phycoerythrin (BD Biosciences, San Jose, CA; clone XMG1.2) and analysed on a Cyan flow cytometer (Dako-Cytomation, Colorado Springs, CO). The gating scheme and analysis were performed essentially as previously described. ${ }^{33}$ The scheme was employed to identify IFN- $\gamma$ production by CD4-positive $\mathrm{T}$ cells excluding doublets, B cells, dendritic cells and monocytes. A minimum of 250000 cellular events were acquired and TCR$\alpha \beta^{+} \mathrm{CD}^{+} \mathrm{CD}^{+}$splenocytes were analysed for intracellular IFN- $\gamma$ using Summit software (Dako-Cytomation, Colorado Springs, CO). Epitope frequency data were subjected to a one-way analysis of variance (ANOVA) and a Bonferroni's multiple comparison post-test. The IFN- $\gamma^{+}$ $\mathrm{CD}^{+} \mathrm{T}$ cells specific for DnaK, IglB and GroEL were compared against the OVA negative control sample. 


\section{Results}

\section{Generation and validation of the STS array}

Forty-five F. tularensis SchuS4 clones of interest were selected from the entry vector library for inclusion in the STS array and shuttled to the arabinose inducible pBADDEST49 expression vector, which produces a fusion protein with the Francisella ORF fused in-frame with the bacterial protein THIO, as well as V5 and $6 \times$ His tags (Fig. 1a). The selected clones were arrayed in a 96-well plate (Fig. 1b). We took advantage of the presence of THIO and the V5 tag, which are present on the expressed proteins to evaluate protein production and purification by blotting an aliquot of each purified protein onto nitrocellulose and probing with an anti-THIO or an anti-V5 antibody (Fig. 1c,d) as described in the Materials and methods. These blots illustrate that all of the proteins were produced, albeit at different levels. We also evaluated the array using antisera that should react to many Francisella protein(s). We used an anti-Tul4 antiserum that was generated in mice that were immunized with an adenoviral vector expressing Tul4 (Adeno-Tul4). This antiserum served as both a positive and negative control; it specifically reacted with Tul4 as can be seen in the strong signal on the spot corresponding to Tul4 (FTT0901), whereas little or no reactivity was seen against the other expressed Francisella proteins blotted onto the membrane (Fig. 1e). A replicate dot blot containing proteins from the same 45 clones was probed with an antiserum from mice that had recovered from infection and re-challenge with F. tularensis LVS. As seen in
Fig. 1(f), almost all of the proteins in the STS array were specifically recognized by convalescent $F$. tularensis sera (compare Fig. 1e,f) illustrating that these are serological targets as a result of Francisella infection.

\section{Identification of IglB-, GroEL- and DnaK-specific hybridomas}

We reasoned that proteins that were also serological targets might also contain T-cell epitopes based on the phenomenon of linked recognition, in which T-cell and B-cell epitopes are found in the same molecule. We therefore screened this serologically validated array against a panel of hybridomas reactive with F. tularensis LVS. For this study we adapted the T-cell antigen discovery assay, which we have previously used successfully to identify epitopes in Tul4. ${ }^{32,33}$ Screening the STS array was accomplished by selecting hybridomas that exhibited reactivity against both $F$. tularensis LVS and SchuS4 lysates, because the hybridomas were made from mice immunized with LVS, but the array was constructed from the SchuS4 strain. In the panel of 30 hybridomas we screened, we were able to identify three hybridomas that were also activated by one of the 45 STS array proteins. Figure 2 illustrates a subset of the screen showing the positive wells, as well as some representative negative wells. For these experiments we duplicated the clones such that each of the 45 clones was replicated within a 96-well plate to provide enhanced reliability for any positive reactivity observed. This also allowed us to test the feasibility of screening in a 96-well format that would be amenable to a high-throughput screen. The FT14 1A5D6 hybridoma

(a)

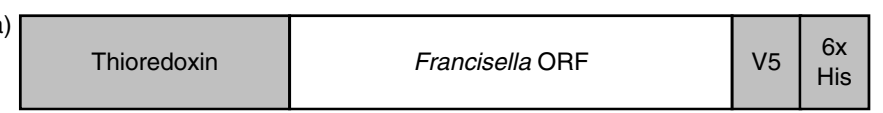

(b)

\begin{tabular}{|c|c|c|c|c|c|c|c|c|c|c|c|}
\hline $1^{69^{5}}$ & $0^{6^{0}}$ & $88^{5^{c}}$ & $1^{1^{6^{\circ}}}$ & $\hat{1}^{1^{8^{0}}}$ & $8^{89^{c}}$ & $\sqrt{1^{16^{0}}}$ & $1^{6^{3^{0}}}$ & बी & $0^{90^{1}}$ & $0^{60^{\circ}}$ & $0^{\hat{x}^{2}}$ \\
\hline$\hat{\wedge}^{\hat{\hat{\alpha}^{1}}}$ & $5^{12^{\circ}}$ & $\sqrt{5} 3^{3^{\circ}}$ & $0^{86^{3^{c}}}$ & $3^{\lambda^{x^{0}}}$ & $\leqslant 5^{0^{0}}$ & $\lambda^{\lambda^{2}}$ & $3^{2^{5}}$ & $0^{86^{9}}$ & $0^{68^{\circ}}$ & $0^{3^{1^{x}}}$ & $1^{60^{60}}$ \\
\hline $0^{19^{6^{6}}}$ & $0^{0^{18}}$ & $2^{2^{6}}$ & $1^{0^{3}}$ & $0^{50}$ & $+\lambda^{0^{6^{c}}}$ & $0^{80^{3}}$ & $0^{8^{1^{c}}}$ & $00^{19}$ & ô & $\wedge^{20}$ & $3^{3}$ \\
\hline $2^{3^{3^{c}}}$ & $1^{6^{90}}$ & $1^{50^{\circ}}$ & $2^{8^{80}}$ & $\lambda^{6^{9}}$ & $1^{50}$ & $\sqrt{52^{6^{0}}}$ & $\hat{\imath}^{2^{0}}$ & $\sqrt{50^{\circ}}$ & & & \\
\hline
\end{tabular}

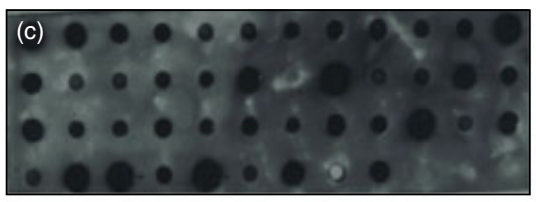

(e)

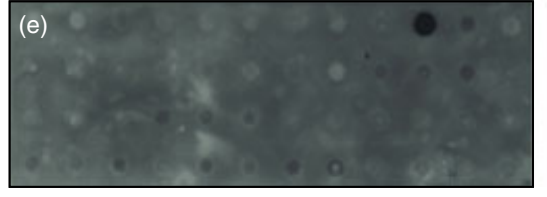

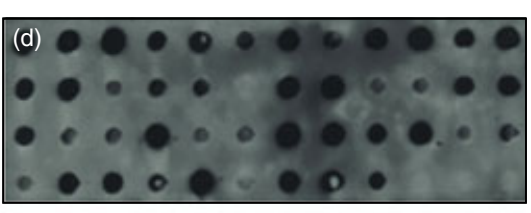

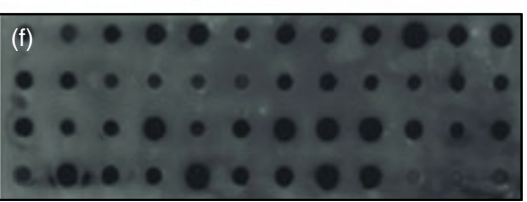

Figure 1. Validation of the proteins in the Serological Target Subset (STS) array. (a) Schematic of a pBAD-DEST49 fusion protein. (b) Forty-five Francisella tularensis SchuS4 genes of interest were selected for the STS array. The grid represents the location within the 96-well plate of each gene, shown as the FTT designation. Empty wells were also left available for in-plate controls. (c-f) Proteins from STS array were expressed and purified, and an aliquot of each was blotted onto nitrocellulose using a dot blot apparatus. Membranes were then probed with anti-thioredoxin antibody (c), anti-V5 antibody (d), antisera from AdenoTul4 immunization (e) or with antisera from mice that had recovered from $F$. tularensis LVS infection ( $\mathrm{f}$ ), followed by detection with rabbit anti-mouse IgG conjugated to horseradish peroxidase. 
exhibited low reactivity to the majority of proteins from the array except for the proteins derived from well C12 and its replicate G12 (Fig. 2a), which correspond to IglB. In a similar fashion, the FT9 hybridoma showed little reactivity except for the two replicate wells $\mathrm{D} 2$ and $\mathrm{H} 2$, which correspond to protein GroEL (Fig. 2b). Finally, the hybridoma FT6 2B7 was activated by the replicate wells D5 and H5, identified as the protein DnaK, while the other wells had very low to negative reactivity (Fig. 2c). By replicating the proteins in the top and bottom halves of the plate, any potential positive will occur as two
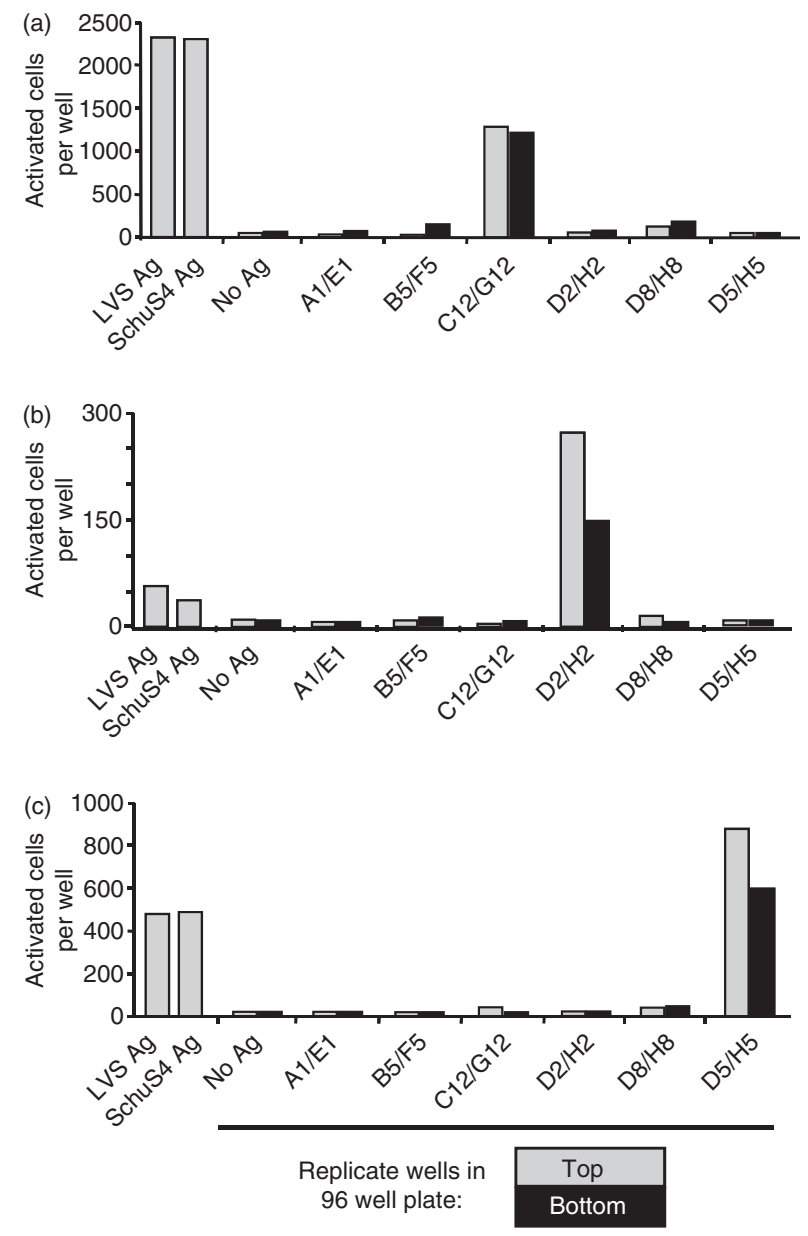

Figure 2. Identification of hybridomas that react with the IglB, GroEL and DnaK proteins. The FT14 1A5D6 (a), FT9 (b) or FT6 2 B7 (c) T-cell hybridomas were incubated in separate plates with C57BL/6 splenocytes and proteins from the Serologic Target Subset (STS) array conjugated to tosyl-activated beads. After overnight incubation, a $\beta$-galactosidase assay was carried out to identify activated LacZ $Z^{+}$cells. For screening experiments, each of the 45 proteins in the STS array was duplicated in a 96-well plate (one replicated in top half, one replicated in bottom half of plate). Francisella tularensis LVS and SchuS4 lysate controls, no antigen wells, as well as, a selection of 10 negative wells from the plate are shown for reference against the replicate wells that are positive for hybridoma activation. This experiment was conducted twice for all hybridomas with similar results. reactive wells while the rest of the wells serve as negative controls, strengthening the putative identification.

Francisella novicida transposon mutants can be used to independently confirm the identification of hybridoma reactivity

Recently a transposon (Tn) mutant library was constructed and characterized in F. novicida U112. ${ }^{39}$ This library was created using transposable elements to disrupt all the non-essential genes in F. novicida U112, and the resulting insertional mutants were isolated and characterized to generate an ordered library where each gene is represented by one or two independent Tn mutants. ${ }^{39}$ Cell lysates made from the Tn mutant clones containing a genetic disruption in a specific ORF, depending upon the location of transposon insertion, would be expected to result in partial or complete loss of expression of the encoded protein. The lack of expression of the specific protein in the lysates should in turn result in a loss of hybridoma reactivity, serving as an independent mechanism for validating hybridoma specificity. We reasoned that we might be able to use this library if the epitopes recognized by the hybridomas were conserved between F. novicida U112 and LVS and that lysates expressed the protein at sufficient levels to activate the hybridomas. All three hybridomas were activated by LVS lysates as expected, but they were also activated by the F. novicida lysate, indicating that the specific epitopes they recognized were conserved (Fig. 3). Having demonstrated that the F. novicida U112 lysates were able to activate the hybridomas we took advantage of the F. novicida Tn mutant library in an effort to verify hybridoma specificity. We found that the FT14 1A5D6 hybridoma could be activated by $\mathrm{Tn}$ mutant lysates (217 and 407 ) where the $i g l C$ gene was disrupted but where the $i g l B$ gene was intact, whereas the $\operatorname{IglB}$ Tn mutant lysates (163 and 773) did not activate the hybridoma, supporting the finding that IglB is the antigen that this hybridoma recognizes (Fig. 3a). Similarly, as expected for a GroEL-specific hybridoma, the FT9 hybridoma showed little reactivity against GroEL Tn mutant lysates (1526) where the GroEL protein was disrupted, but was capable of being activated by $\mathrm{Tn}$ mutant lysates (217 and 407) where the groEL gene was intact (Fig. 3b). The results with the hybridoma we had identified as being reactive with DnaK were not as conclusive. Although the DnaK Tn mutant (775) lysate was lower than the parental strains, the IglC Tn mutants were also somewhat lower than the parental strains (Fig. 3c). These data, although suggesting that the hybridoma reacts with DnaK, were not as definitive as for the other two hybridomas. Nonetheless, the F. novicida Tn mutant experiments provide an independent method that further supports hybridoma reactivity identification, and in particular, the specificity 

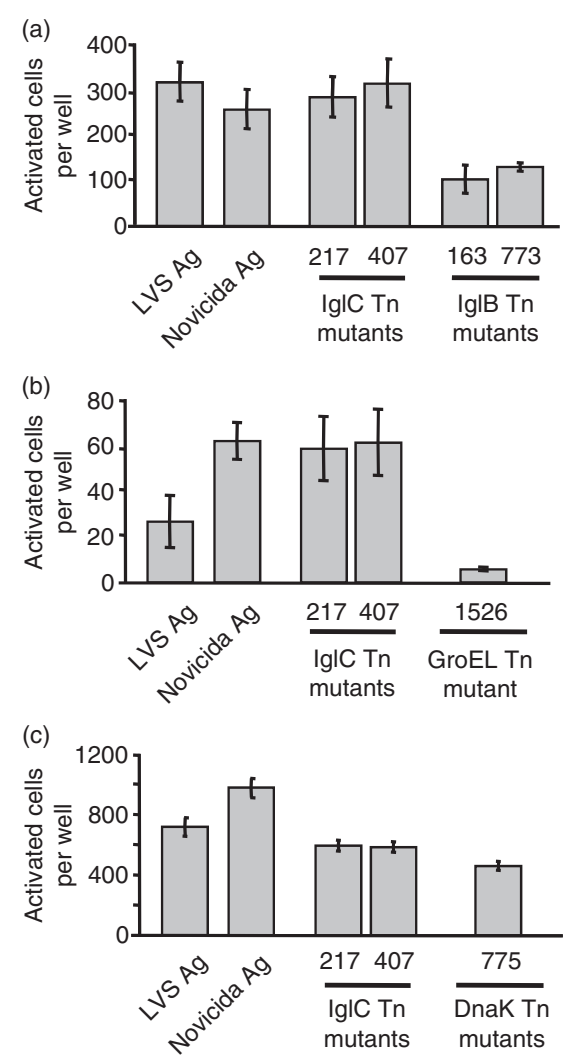

Figure 3. Genetic evidence for hybridoma specificity. FT14 1A5D6 hybridoma (a), FT9 hybridoma (b), or FT6 2B7 hybridoma (c) were incubated with splenocytes from C57BL/6 mice and lysates from Francisella tularensis LVS (LVS Ag), F. novicida U112 (Novicida Ag) or F. novicida U112 transposon mutant clones (indicated with Tn). After overnight incubation, a $\beta$-galactosidase assay was conducted to identify and enumerate activated cells. These experiments have been conducted two or more times with similar results, quadruplicate wells per treatment were counted and the average activated cells per well are shown.

of FT14 1A5D6 for the protein IglB and FT9 for the protein GroEL.

\section{Identification of an epitope region in IglB using deletion constructs}

The FT14 1A5D6 hybridoma was used in antigen presentation assays to map the region within IglB that contains a Tcell epitope recognized by the hybridoma. To do so, a series of IglB deletion constructs were generated, expressed and used in antigen presentation assays. Figure 4(a) shows that the FT14 1A5D6 hybridoma is activated when the entire IglB protein (1-514) is present, but unable to be activated by any of the smaller fragments including the fragment containing the amino acids $1-390$ of IglB, indicating that the epitope was probably within the amino acids 390-514. To refine our epitope search, fragments of IglB spanning the region from amino acids 386 to 514 were produced.
When these IglB fragments were screened, we found that the FT14 1A5D6 hybridoma could be activated by amino acids $454-514$, but no reactivity was seen against amino acids $386-433$ or $426-471$, indicating that the epitope recognized is found within residues 454-514 (Fig. 4b). The stimulatory 454-514 fragment could be further refined to omit the 17 amino acids that are shared with the non-stimulatory 426-471 fragment, because if these 17 residues contained an epitope, both fragments would have elicited hybridoma activation. Hence, these results indicate that residues 471-514 of IglB contains the epitope recognized by the FT14 1A5D6 hybridoma.

\section{Identification of epitope regions within GroEL and DnaK}

To map the epitope regions within GroEL and DnaK recognized by the FT9 and FT6 2B7 hybridomas, respectively, we used the same general approach discussed above for IglB mapping. As seen in Fig. 4(c), the FT9 hybridoma is not only activated by full-length GroEL (1-545) but also by the fragment 360-545 and it is not activated by the other fragments, indicating that the epitope recognized was found within amino acids 360-545 of GroEL. Using fine mapping fragments the reactivity seen against the 360-545 region was further refined to residues 409-492, which can be further limited to residues $441-480$ based on reactivity to deletion constructs (Fig. 4d). As seen in Fig. 4(e), the FT6 2 B7 hybridoma can be activated by full-length DnaK (1-643), as well as, the fragment containing residues 1-177. Fine mapping of the 1-177 region showed that fragments 1-122 and 109-177 were capable of activating the hybridoma, indicating that the epitope could be found within the 14 residues shared between these constructs, amino acids 109-122 (Fig. 4f). Hence, we have identified the regions 441-480 of GroEL and 109-122 of DnaK to contain T-cell epitopes.

\section{Peptide validation of hybridoma specificity}

To validate the results of the mapping studies using recombinant protein we had a set of IglB, GroEL and DnaK peptides synthesized based upon the fine mapping data (Fig. 4b-d) and aided by in silico prediction algorithms, as described in the Materials and methods. In all peptide reactivity assays, hybridoma reactivity was not seen against irrelevant peptide controls or the no antigen negative control (Fig. 5). IglB protein mapping data (Fig. 4a,b), together with the peptide predictions, enabled us to refine our search to three peptides within the amino acids 472-489, of which the peptide IglB 475-489 had the greatest stimulatory capability, and to a lesser degree the peptides containing residues $472-486$ and $475-486$ of IglB (Fig. 5a). These data conclusively show that the FT14 

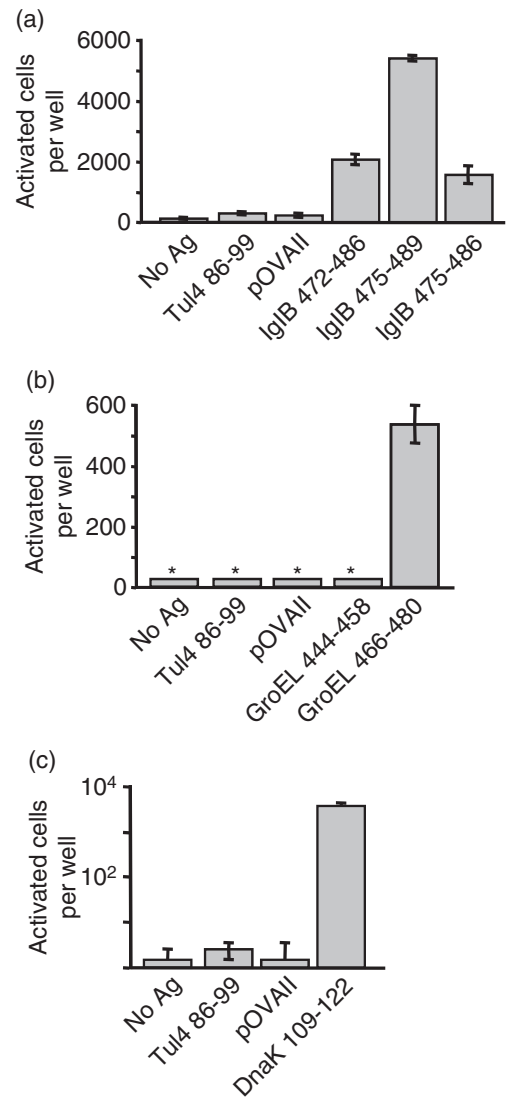

Figure 4. Fine mapping hybridoma specificity using fusion proteins made from deletion constructs. Hybridomas were incubated with C57BL/6 splenocytes and proteins were conjugated to tosyl-activated beads. No antigen wells, THIO-IglC, or DHFR-OVA were included as negative controls. The FT14 1A5D6 hybridoma was used for screening IglB deletion proteins (a) and fine mapping experiments (b). The FT9 hybridoma was used for screening GroEL fragments (c) and fine mapping experiments (d). The FT6 2B7 hybridoma was used for screening DnaK fragments (e) and fine mapping experiments (f). After overnight incubation, a $\beta$-galactosidase assay was carried out to identify and enumerate activated cells. Quadruplicate wells per protein were counted and the average activated cells per well were presented as representative data from two experiments for each hybridoma.

1A5D6 hybridoma derived from a mouse following live infection recognizes an epitope within the amino acids 472-489 of IglB, with residues 475-489 being capable of maximal activation. GroEL protein mapping data (Fig. 4c,d) together with the in silico MHC-binding prediction identified two peptides as putative epitopes. These peptides were screened for reactivity against the FT9 hybridoma and we found that only the peptide containing residues 466-480 of GroEL was able to activate the hybridoma, identifying this peptide as the epitope recognized (Fig. 5b). In a similar fashion, the DnaK mapping data (Fig. 4e,f) strongly indicated that the epitope recognized by the FT6 $2 \mathrm{~B} 7$ hybridoma was contained within residues 109-122. As expected, the peptide DnaK
109-122 was capable of activating the FT6 2B7 hybridoma, indicating that it is indeed the epitope recognized (Fig. 5c).

\section{Assessment of IglB 475-489, GroEL 466-480 and DnaK 109-122 epitope frequency in vivo}

By using T-cell hybridomas stimulated by an infection, the epitopes identified are inherently validated as being natural T-cell epitopes. However, this approach does not address whether or not the epitope is dominant within the response or a comparatively rare event, perhaps recognized by relatively few $\mathrm{T}$ cells. To determine the frequency of $\mathrm{T}$ cells that recognize the IglB, GroEL and DnaK epitopes, we examined the F. tularensis response using intracellular IFN $-\gamma$ in $\mathrm{CD} 4^{+}$ $\mathrm{T}$ cells from mice acutely infected with Francisella, mice immunized with a mixture of IglB, GroEL and DnaK peptide epitopes and rested, or from mice primed with the mixture of peptide epitopes and challenged with F. tularensis LVS. Spleen cells were stimulated ex vivo with $F$. tularensis lysates (FT Ag) or with the individual peptides and were stained with an array of cellular markers followed by multicolour flow cytometry to identify activated IFN $-\gamma^{+} \mathrm{CD} 4^{+}$ $\mathrm{T}$ cells and exclude B cells, dendritic cells and monocyte populations from the analysis. As shown in Fig. 6(a), 40 days after immunization, the $\mathrm{CD}^{+}$splenocytes from mice that were immunized with only peptide mixture after this extended rest failed to produce IFN- $\gamma$ when stimulated with FT Ag or any peptides directly ex vivo. Splenocytes from mice that had been acutely infected with $F$. tularensis LVS and isolated at the height of the primary response produced IFN- $\gamma$ when stimulated with Francisella extracts (FT $\mathrm{Ag}$ ) as expected, however, the DnaK, IglB and GroEL peptides did not stimulate a detectable number of $\mathrm{CD} 4^{+} \mathrm{T}$ cells to produce IFN- $\gamma$, with the exception of one out of the three mice generating splenocytes that were stimulated by the GroEL 466-480 peptide (Fig. 6b). It was of particular interest to determine whether immunization with the identified peptides could augment the frequency with which each epitope is recognized during a live $F$. tularensis infection. Mice were primed with the peptide mixture immunization followed by $F$. tularensis LVS infection 3 weeks later. Splenocytes from these mice were harvested 10 days after infection, stimulated, and analysed as described above. As expected, $\mathrm{CD}^{+}$splenocytes from these mice also produced IFN- $\gamma$ when stimulated with FT Ag and the total frequency of $\mathrm{CD} 4^{+}$IFN $-\gamma^{+}$cells was similar to that seen in mice from infection alone (Fig. 6c). Interestingly, when the mice were inoculated with F. tularensis LVS following a peptide prime, the frequency of IglB epitope-specific T cells recognized was significantly increased $(P<0.05)$ compared with the frequency seen in infection alone, while DnaK-specific $\mathrm{T}$ cells were increased but failed to reach statistical significance (Fig. 6c). These results suggest that the epitopes arise at a low level during a primary infection but can be readily 

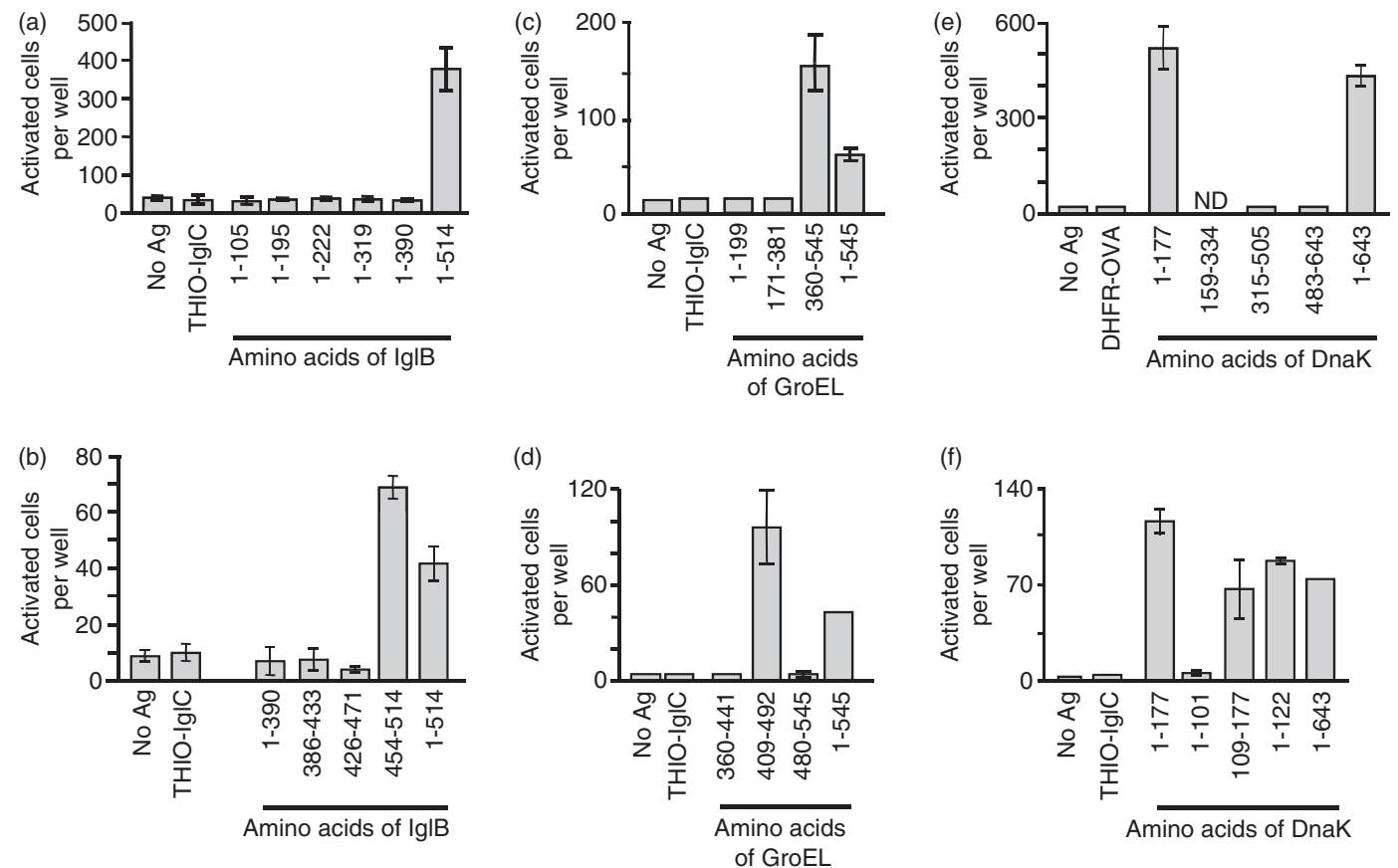

Figure 5. Epitope mapping using peptides. Hybridomas were incubated with C57BL/6 splenocytes without antigen or with irrelevant peptide controls Tul4 86-99 or pOVAII peptide. (a) FT14 1 A5D6 hybridomas were also incubated with IglB 475-489, IglB 472-486, or IglB 475-486 peptides. (b) FT9 hybridomas were also incubated with GroEL 444-458, or GroEL 466-480 peptides. (c) FT6 2 B7 hybridomas were incubated with DnaK 109-122 peptide. After overnight incubation, a $\beta$-galactosidase assay was performed to identify activated cells. Four replicates per treatment were done per experiment, a repeat of two experiments is shown. Average number of activated cells per well and standard deviation from a representative experiment have been shown. Asterisk denotes which were plotted away from the axis, because of extremely low reactivity in the particular wells, for clarity.

recognized after peptide priming in the context of a secondary challenge. Reactivity to the peptide immunization could not account for these findings because mice immunized with a peptide mixture alone did not result in much residual T-cell reactivity (Fig. 6a).

\section{Discussion}

We set out to develop a method to identify T-cell epitopes using a combination of genomics and a functional screen for T-cell activation employing a solid-phase antigen delivery system. Previously, we have used a variation of this approach to identify epitopes in single target proteins. ${ }^{32,33}$ In the current study, we took advantage of the availability of a library of $F$. tularensis SchuS4 ORFs constructed in a Gateway entry vector to develop a methodology that could be scaled to a large number of clones. To test the feasibility of this approach for high-throughput screening using the Gateway cloning system, a subset of 45 clones from the arrayed library of entry clones, termed the STS array, was shifted into the bacterial expression vector pBAD-DEST49. This expression vector also encodes a $6 \times$ His tag allowing for the expressed proteins to be isolated in a semi-automated procedure using Ni-NTA columns. ${ }^{40}$ The purified proteins could then be coupled to beads to deliver antigens to APC in a modified T-cell antigen discovery assay, previously used in our laboratory. ${ }^{32,33}$ This solid-phase antigen delivery system is an extremely efficient means by which to deliver antigen to $\mathrm{APC}^{41-43}$ and because these APC process and present the antigen, they can be used in a functional screen with T-cell hybridomas. The majority of the 45 STS array clones were chosen because previous works showed that they were targets of an antibody response to Francisella. ${ }^{34-37}$ By choosing proteins that were serological targets, we were able to independently validate their expression using serum from $F$. tularensis LVS-infected and -challenged animals (see Fig. 1). Furthermore, because the STS proteins are targets for antibodies, this indicates that Francisella expressed these proteins in the host. We also reasoned that molecules that contained Bcell epitopes might also contain T-cell epitopes because of linked recognition and indeed we were able to identify Tcell antigens using this approach. Although a more comprehensive analysis is needed to determine if the STS proteins are enriched in T-cell epitopes, it is interesting that the reactivity of three out of 30 hybridomas could be identified with this approach. Recently this concept of linked recognition in complex pathogens received experimental support from a study finding that vaccinia virus antigen that contained $\mathrm{CD}^{+}$T-cell epitopes was also associated with antibody reactivity. ${ }^{44}$ 

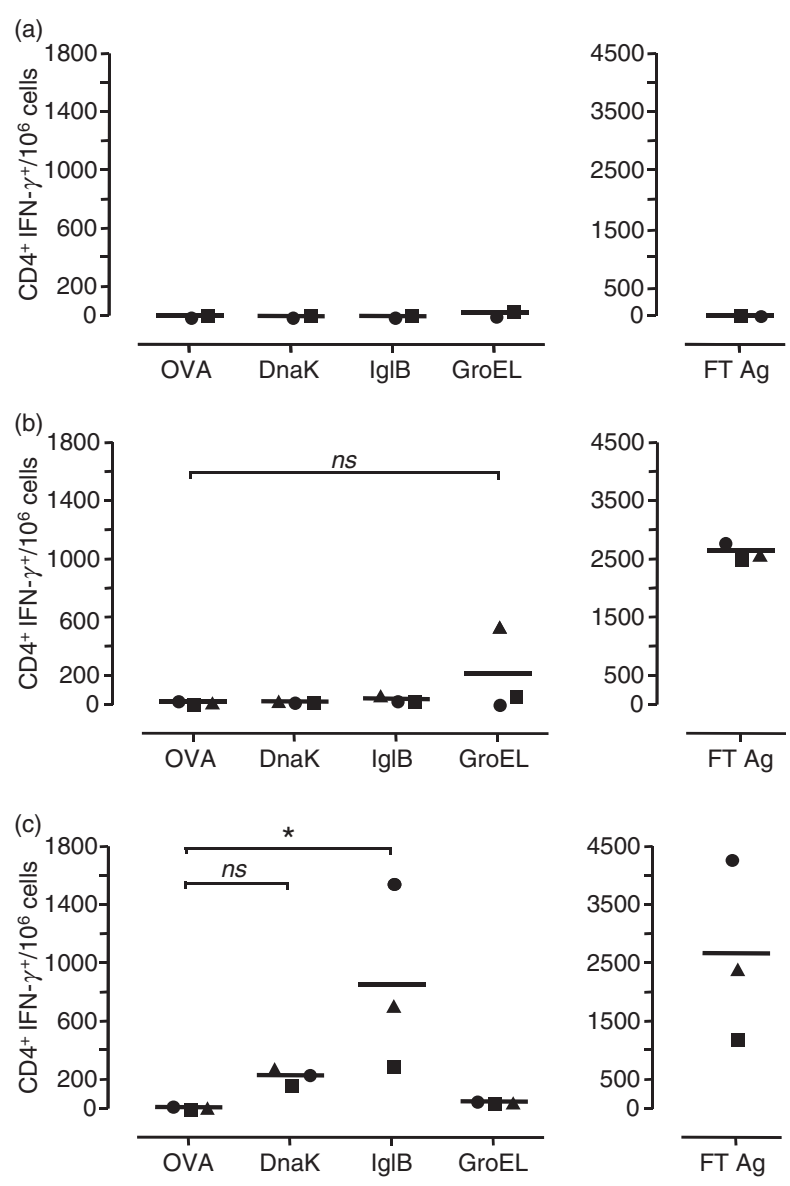

Figure 6. Assessment of epitope frequency in vivo. Splenocytes were harvested from mice that were either immunized with a peptide mixture only (a), sham immunized and challenged with Francisella tularensis LVS (b), or immunized with a peptide mixture and challenged with F. tularensis LVS. (c) Splenocytes were stimulated briefly with lysate from F. tularensis LVS (FT Ag) as a positive control and various peptides; DnaK 109-122, IglB 475-489, and GroEL 466-480. OVA 323-339 peptide was included as a negative control. Brefeldin was introduced for the last $4 \mathrm{hr}$ of culture. Splenocytes were then stained with fluorescent antibodies, as described in the Materials and methods, and analysed for $\mathrm{CD}^{+}{ }^{+}$IFN- $\gamma^{+}$cells using FACS. Symbols represent stimulation data from individual mice within the different immunization groups and are graphed as $\mathrm{CD} 4^{+} \mathrm{IFN}-\gamma^{+}$double-positive cells per $10^{6}$ splenocytes. Asterisk, $P<0.05 ; n s$, not significant.

The three molecules we identified in the initial screen as containing T-cell epitopes were also confirmed by a genetic approach that took advantage of an arrayed Tn mutant library of F. novicida. ${ }^{39}$ This library has been useful for a variety of studies including the identification of virulence determinants. ${ }^{45,46}$ Here we have used the Tn mutants as a source of protein knockout lysate, with the rationale that cellular extracts made from the Tn mutant clones should be deficient in the molecule encoded by the transposon disrupted gene and so would test if the T-cell hybridoma recognized this antigen. The availability of the arrayed library of Tn mutants provided a straightforward means of independently confirming this approach, although it should be noted that there are several potential caveats to this strategy. For example, as the library used in the current study was made in a different species of Francisella, it was important to confirm that the T-cell hybridomas could recognize the F. novicida antigen. Our experiments found that the hybridomas were in fact cross-reactive for the three molecules, probably because of the high degree of genetic similarity and protein homology between the strains of Francisella. ${ }^{8}$ Indeed, the sequences of all three epitopes we identified are identical in F. tularensis SchuS4, F. tularensis LVS and F. novicida. Additionally, it should be noted that the Tn mutants might potentially express a fragment of the disrupted protein, which could still activate the hybridoma, or that a mutation in one gene might affect the expression of other gene products. Nevertheless, despite these potential concerns, we found that two out of the three proteins examined using this approach confirmed our initial assignment; whereas in the case of DnaK these analyses gave a suggestive, but not definitive, answer (see Fig. 3 ). A retrospective analysis of the epitope location compared with Tn insertion provides a potential explanation for this finding. The identified epitope in DnaK is located upstream from the insertion of the transposable element, which might result in potential protein fragments containing the recognized epitope and hybridoma reactivity. The ultimate validation and identification of the epitopes was also supported using analyses of protein fragments and the chemical synthesis of the peptide combined with biological functionality testing.

Here we report that using the approach described above we have been able to identify epitopes in the proteins GroEL, DnaK and IglB. It is interesting that two of the epitopes we identified are in the chaperone proteins DnaK and GroEL. These were previously identified as strong serological targets ${ }^{37,47}$ and in our analyses these also showed strong antibody reactivity in serum that had been primed and challenged with live F. tularensis LVS (see Fig. 1f). Indeed, an extensive analysis of primary immunization strategies examining the humoral response resulting from live infection or from immunization with killed $F$. tularensis LVS adjuvanted with ISCOMS, CpG or ALUM strategies listed GroEL as the number one target of antibody reactivity, whereas DnaK was listed as number $21 .^{37}$ Additionally, a long-lasting CD4 and CD8 T-cell recall response to F. tularensis heat-shock proteins, including DnaK and GroEL, has been shown in humans ${ }^{48}$ and a significant cell-mediated response was seen against GroEL in mice although the epitopes were not identified. ${ }^{49}$ Interestingly, F. tularensis GroEL was recently shown to have adjuvant-like activity that synergized with lipopolysaccharide from Francisella to activate human macrophages. ${ }^{50}$ It is intriguing that chaperone proteins have been suggested to have adjuvant activity leading them to be immunostimulatory, which could poten- 
tially impact an immune response. ${ }^{51-53}$ Finally, from an immunological standpoint they are also interesting targets because they are evolutionarily conserved and a response directed to a chaperone protein has the possibility to be cross-reactive with several other bacterial species.

The identification of a T-cell epitope in IglB is interesting in that it is, to our knowledge, the first direct validation of a molecular epitope in a Francisella pathogenicity island (FPI) protein. After entry into macrophages or dendritic cells, FPI proteins are crucial for the ability of Francisella to escape the phagolysosomal compartment and the capability for replication within the host cytosol. ${ }^{54-56}$ Indeed, recent studies using iglB mutants show impaired intracellular replication and phagosomal escape, resulting in an attenuated infection in mice and Drosophila melanogaster models, implicating IglB as a crucial factor for virulence and pathogenicity. ${ }^{46,57-60}$ Intriguingly, IglB was recently shown to be one of the earliest of the FPI proteins up-regulated when Francisella is within macrophages. ${ }^{61}$ Furthermore, other studies have shown that IglB interacts with other pathogenicity island proteins either directly, for example with the protein IglA, or complexed with proteins such as IglC and PdpD. ${ }^{62-64}$ The proteins IglA and IglB share homology with proteins of the newly defined Type VI secretion system (T6SS), a system identified in nearly 100 Gram-negative bacteria species. ${ }^{64-66}$ A recent study by Barker et al. ${ }^{67}$ has provided additional evidence supporting the homology of the FPI to T6SS and has also identified secreted effectors, VrgG (FTT1347) and IglI (FTT1352), providing evidence that FPI genes may be components of a secretory system. As speculated in Broms et al., IglB may be part of a T6SS apparatus that associates with IglA to secrete the effector molecules, for example IglC, a crucial virulence factor, ${ }^{58,68}$ into the host cell to modulate phagosomal escape and allow infective propagation. ${ }^{62}$

Interestingly, our immunization data (see Fig. 6) would suggest that the epitopes identified might be considered subdominant or cryptic in the context of a live infection. ${ }^{69-}$ ${ }^{71}$ Although there appeared to be a response to GroEL in a primary response to live LVS infection in one animal, overall, $\mathrm{T}$ cells recognizing these epitopes were only present at relatively low frequency in the primary immune response infection, when compared with the epitope frequency seen against the lipoprotein Tul4 we reported previously. ${ }^{33}$ However, after immunization with a mixture of the peptide epitopes we identified, T-cell responses to IglB, and to a lesser degree DnaK, could be recalled by a live infection (see Fig. 6). Of the newly identified epitopes, the IglB epitope shows the greatest amount of reactivity. Whether or not this is the result of a characteristic of IglB expression, such as protein level, or when it is expressed during infection remains to be determined. It is particularly intriguing that IglB can be recognized because FPI proteins are potentially good candidates for vaccines. As mentioned above, deletion of FPI proteins often results in decreased virulence ${ }^{54,56,68}$ so it would not be easy for bacteria to evade an immune response by deleting the target antigen. A recent study showed that immunization with live recombinant Listeria expressing IglC provided protection against a live aerosol challenge of F. tularensis SchuS4, although the epitopes were not identified by that study. ${ }^{72}$ The identification of epitopes, including the IglB epitope described here, should aid in the investigation of various vaccine strategies including ones that might target FPI proteins, as it is likely an effective vaccine would need to target multiple epitopes and also stimulate humoral immunity. ${ }^{28,73,74}$

Whether any of the epitopes we identified are protective remains to be determined. The protein sequences encoding these epitopes are conserved across the F.tularensis SchuS4, F. tularensis LVS, and F. novicida strains, which is interesting to consider in light of the protection provided by these different strains with infection. The F. tularensis LVS strain has been shown to provide partial protection against F. tularensis SchuS4, suggesting that shared epitopes could be involved in protection. ${ }^{7}$ On the other hand, Cong et al. ${ }^{57}$ using an iglB gene-deleted F. novicida strain showed only limited protection against F. tularensis SchuS4. This might suggest that private epitopes unique to F. tularensis SchuS4 are needed to provide optimal protection. However, it is also important to consider that differences in the biology of the different strains of Francisella, such as the nature of the innate response to infection, might also play important roles in their immunogenicity, as well as pathogenicity. While the nature of protective Tcell responses to Francisella is relatively poorly understood, the identification of epitopes will nevertheless greatly aid in elucidating the kinetics and magnitude of T-cell responses to this organism. Further studies will be required to determine which epitopes are protective.

There are a variety of methods to identify epitopes. ${ }^{75-86}$ By using a functional screen using $\mathrm{T}$ cells to identify epitopes, the method used here immediately validates that they are authentic T-cell epitopes. Further, because this approach does not make any a priori assumptions, one can identify epitopes that are not easily predicted by MHCbinding algorithms. Indeed, we analysed the IglB, GroEL and DnaK proteins retrospectively using several epitopepredicting website algorithms (IEDB: Arbpython and SMM-align; Rankpep; and NetMHCII 2.0: NN-Align), and found that the different algorithms gave dramatically different predictions for peptide epitope characteristics, such as, the total number of epitopes, core sequence and binding affinity. ${ }^{87}$ Moreover, we found that no one algorithm entirely predicted the epitopes we identified using the functional screen. For example the IglB epitope, which was the strongest epitope to be recalled by live infection, was successfully predicted by the Rankpep algorithm only (predicted binding threshold $>9.52$ ), whereas all other binding algorithms indicated that the peptide would be a weak binder at best (binding affinity $\mathrm{IC}_{50}>5000 \mathrm{~nm}$ ). Neverthe- 
less, we would emphasize that the use of immunoinformatics tools and the unbiased functional screens we have employed are complementary methods. Indeed, we routinely take a combinatorial approach, having found that once we have mapped T-cell reactivity to a relatively small region using the deletion protein technique, the algorithms are extremely helpful in designing peptides to test. The approach employed in the current study, in which the antigen is first expressed and purified, and subsequently delivered to APC for processing and presentation, has features that make it particularly attractive and versatile in several contexts. For example, once the proteins are expressed and purified they not only can be used in an arrayed format to characterize antibody responses, ${ }^{37}$ but also used as immunogens themselves. We have used this approach to characterize T-cell epitopes in F. tularensis previously for Tul $4^{33}$ and more recently applied this approach to IglC (data not shown). Importantly, once the proteins are expressed and purified, they can be used to identify epitopes in different mouse strains with varying MHC haplotypes. This approach should also be applicable to HLA transgenic mice, which can be used to model human immune responses because the proteins are delivered to APC for processing rather than using panels of peptides designed to bind specific MHC molecules. ${ }^{88}$ Finally, this approach is scalable to thousands of clones. The methods we have presented here, and ever increasing availability of genomic resources, will ultimately make this approach feasible for characterizing immune responses to a variety of organisms.

\section{Acknowledgements}

We thank Dr Colin Maniol for the F. novicida transposon mutant library. This work has been supported in part by funds from the National Institutes of Health contract NO1-AI-40086, NIH/NIAID Southeast Regional Center of Excellence for Emerging Infections and Biodefense (SERCEB) (grant no. U54 AI 057157); M.V. was supported by NIAID training grant T32-AI-007362-17 and M.D.W. was supported by NIAID AI-007062.

\section{Disclosures}

None of the authors involved with this work has any financial interest or any conflict of interest to disclose.

\section{References}

1 Sjostedt A. Tularemia: history, epidemiology, pathogen physiology, and clinical manifestations. Ann N Y Acad Sci 2007; 1105:1-29.

2 Oyston PC, Sjostedt A, Titball RW. Tularaemia: bioterrorism defence renews interest in Francisella tularensis. Nat Rev Microbiol 2004; 2:967-78

3 Titball RW, Petrosino JF. Francisella tularensis genomics and proteomics. Ann N Y Acad Sci 2007; 1105:98-121.

4 Elkins KL, Cowley SC, Bosio CM. Innate and adaptive immune responses to an intracellular bacterium, Francisella tularensis live vaccine strain. Microbes Infect 2003; 5:135-42.
5 Elkins KL, Cowley SC, Bosio CM. Innate and adaptive immunity to Francisella. Ann N Y Acad Sci 2007; 1105:284-324.

6 Rick Lyons C, Wu TH. Animal models of Francisella tularensis infection. Ann N Y Acad Sci 2007; 1105:238-65.

7 Pechous RD, McCarthy TR, Zahrt TC. Working toward the future: insights into Francisella tularensis pathogenesis and vaccine development. Microbiol Mol Biol Rev 2009; 73:684-711.

8 Champion MD, Zeng Q, Nix EB et al. Comparative genomic characterization of Francisella tularensis strains belonging to low and high virulence subspecies. PLoS Pathog 2009; 5:e1000459.

9 Keim P, Johansson A, Wagner DM. Molecular epidemiology, evolution, and ecology of Francisella. Ann N Y Acad Sci 2007; 1105:30-66.

10 Molins CR, Delorey MJ, Yockey BM et al. Virulence differences among Francisella tularensis subsp. tularensis clades in mice. PLoS ONE 2010; 5:e10205.

11 Woolard MD, Wilson JE, Hensley LL, Jania LA, Kawula TH, Drake JR, Frelinger JA. Francisella tularensis-infected macrophages release prostaglandin E2 that blocks $\mathrm{T}$ cell proliferation and promotes a Th2-like response. J Immunol 2007; 178:2065-74.

12 Bosio CM, Bielefeldt-Ohmann H, Belisle JT. Active suppression of the pulmonary immune response by Francisella tularensis Schu4. J Immunol 2007; 178:4538-47.

13 Bosio CM, Dow SW. Francisella tularensis induces aberrant activation of pulmonary dendritic cells. J Immunol 2005; 175:6792-801.

14 Chase JC, Celli J, Bosio CM. Direct and indirect impairment of human dendritic cell function by virulent Francisella tularensis Schu S4. Infect Immun 2009; 77:18095.

15 Bublitz DC, Noah CE, Benach JL, Furie MB. Francisella tularensis suppresses the proinflammatory response of endothelial cells via the endothelial protein $\mathrm{C}$ receptor. J Immunol 2010; 185:1124-31.

16 Loegering DJ, Drake JR, Banas JA, McNealy TL, Mc Arthur DG, Webster LM, Lennartz MR. Francisella tularensis LVS grown in macrophages has reduced ability to stimulate the secretion of inflammatory cytokines by macrophages in vitro. Microb Pathog 2006; 41:218-25.

17 Wilson JE, Katkere B, Drake JR. Francisella tularensis induces ubiquitin-dependent major histocompatibility complex class II degradation in activated macrophages. Infect Immun 2009; 77:4953-65.

18 Paranavitana C, Zelazowska E, DaSilva L, Pittman PR, Nikolich M. Th17 cytokines in recall responses against Francisella tularensis in humans. J Interferon Cytokine Res 2010; 30:471-6.

19 Markel G, Bar-Haim E, Zahavy E, Cohen H, Cohen O, Shafferman A, Velan B. The involvement of IL-17A in the murine response to sub-lethal inhalational infection with Francisella tularensis. PLoS ONE 2010; 5:e11176.

20 Woolard MD, Hensley LL, Kawula TH, Frelinger JA. Respiratory Francisella tularensis live vaccine strain infection induces Th17 cells and prostaglandin E2, which inhibits generation of gamma interferon-positive T cells. Infect Immun 2008; 76:2651-9.

21 Conlan JW, Sjostedt A, North RJ. CD4 $4^{+}$and $\mathrm{CD}^{+}$T-cell-dependent and -independent host defense mechanisms can operate to control and resolve primary and secondary Francisella tularensis LVS infection in mice. Infect Immun 1994; 62:5603-7.

22 Elkins KL, Rhinehart-Jones TR, Culkin SJ, Yee D, Winegar RK. Minimal requirements for murine resistance to infection with Francisella tularensis LVS. Infect Immun 1996; 64:3288-93.

23 Tarnvik A, Ericsson M, Golovliov I, Sandstrom G, Sjostedt A. Orchestration of the protective immune response to intracellular bacteria: Francisella tularensis as a model organism. FEMS Immunol Med Microbiol 1996; 13:221-5.

24 Cowley SC, Elkins KL. Multiple T cell subsets control Francisella tularensis LVS intracellular growth without stimulation through macrophage interferon gamma receptors. I Exp Med 2003; 198:379-89.

25 Cowley SC, Hamilton E, Frelinger JA, Su J, Forman J, Elkins KL. CD4 $4^{-} \mathrm{CD} 8^{-}$T cells control intracellular bacterial infections both in vitro and in vivo. J Exp Med 2005; 202:309-19.

26 Cowley SC, Meierovics AI, Frelinger JA, Iwakura Y, Elkins KL. Lung CD4- $4^{-} 8^{-}$ double-negative $\mathrm{T}$ cells are prominent producers of IL-17A and IFN-gamma during primary respiratory murine infection with Francisella tularensis live vaccine strain. J Immunol 2010; 184:5791-801.

27 Yee D, Rhinehart-Jones TR, Elkins KL. Loss of either $\mathrm{CD}^{+}$or $\mathrm{CD}^{+} \mathrm{T}$ cells does not affect the magnitude of protective immunity to an intracellular pathogen, Francisella tularensis strain LVS. J Immunol 1996; 157:5042-8.

28 Kirimanjeswara GS, Olmos S, Bakshi CS, Metzger DW. Humoral and cell-mediated immunity to the intracellular pathogen Francisella tularensis. Immunol Rev 2008; 225:244-55.

29 Metzger DW, Bakshi CS, Kirimanjeswara G. Mucosal immunopathogenesis of Francisella tularensis. Ann N Y Acad Sci 2007; 1105:266-83.

30 Elkins KL, Bosio CM, Rhinehart-Jones TR. Importance of B cells, but not specific antibodies, in primary and secondary protective immunity to the intracellular bacterium Francisella tularensis live vaccine strain. Infect Immun 1999; 67:6002-7. 
31 Anderson RV, Crane DD, Bosio CM. Long lived protection against pneumonic tularemia is correlated with cellular immunity in peripheral, not pulmonary, organs. Vaccine 2010; 28:6562-72.

32 Turner MJ, Abdul-Alim CS, Willis RA, Fisher TL, Lord EM, Frelinger JG. T-cell antigen discovery (T-CAD) assay: a novel technique for identifying $\mathrm{T}$ cell epitopes. J Immunol Methods 2001; 256:107-19.

33 Valentino MD, Hensley LL, Skrombolas D et al. Identification of a dominant CD4 T cell epitope in the membrane lipoprotein Tul4 from Francisella tularensis LVS. Mol Immunol 2009; 46:1830-8.

34 Huntley JF, Conley PG, Hagman KE, Norgard MV. Characterization of Francisella tularensis outer membrane proteins. J Bacteriol 2007; 189:561-74.

35 Havlasova J, Hernychova L, Halada P et al. Mapping of immunoreactive antigens of Francisella tularensis live vaccine strain. Proteomics 2002; 2:857-67.

36 Havlasova J, Hernychova L, Brychta M et al. Proteomic analysis of anti-Francisella tularensis LVS antibody response in murine model of tularemia. Proteomics 2005; 5:2090-103.

37 Eyles JE, Unal B, Hartley MG et al. Immunodominant Francisella tularensis antigens identified using proteome microarray. Crown Copyright 2007 Dstl. Proteomics 2007; 7:2172-83.

38 Sanderson S, Shastri N. LacZ inducible, antigen/MHC-specific $\mathrm{T}$ cell hybrids. Int Immunol 1994; 6:369-76.

39 Gallagher LA, Ramage E, Jacobs MA, Kaul R, Brittnacher M, Manoil C. A comprehensive transposon mutant library of Francisella novicida, a bioweapon surrogate. Proc Natl Acad Sci USA 2007; 104:1009-14.

40 Valentino M, Frelinger J. An approach to the identification of $\mathrm{T}$ cell epitopes in the genomic era: application to Francisella tularensis. Immunol Res 2009; 45:218-28.

41 Rock KL, Clark K. Analysis of the role of MHC class II presentation in the stimulation of cytotoxic T lymphocytes by antigens targeted into the exogenous antigen-MHC class I presentation pathway. J Immunol 1996; 156:3721-6.

42 Shen Z, Reznikoff G, Dranoff G, Rock KL. Cloned dendritic cells can present exogenous antigens on both MHC class I and class II molecules. J Immunol 1997; 158:2723-30.

43 Storozynsky E, Woodward JG, Frelinger JG, Lord EM. Interleukin-3 and granulocytemacrophage colony-stimulating factor enhance the generation and function of dendritic cells. Immunology 1999; 97:138-49.

44 Sette A, Moutaftsi M, Moyron-Quiroz J et al. Selective CD4 $4^{+} \mathrm{T}$ cell help for antibody responses to a large viral pathogen: deterministic linkage of specificities. Immunity 2008; 28:847-58.

45 Kraemer PS, Mitchell A, Pelletier MR et al. Genome-wide screen in Francisella novicida for genes required for pulmonary and systemic infection in mice. Infect Immun 2009; 77:232-44.

46 Ahlund MK, Ryden P, Sjostedt A, Stoven S. Directed screen of Francisella novicida virulence determinants using Drosophila melanogaster. Infect Immun 2010; 78:3118-28.

47 Twine SM, Petit MD, Shen H, Mykytczuk NC, Kelly JF, Conlan JW. Immunoproteomic analysis of the murine antibody response to successful and failed immunization with live anti-Francisella vaccines. Biochem Biophys Res Commun 2006; 346:999-1008.

48 Ericsson M, Kroca M, Johansson T, Sjostedt A, Tarnvik A. Long-lasting recall response of $\mathrm{CD}^{+}$and $\mathrm{CD}^{+} \alpha \beta \mathrm{T}$ cells, but not $\gamma \delta \mathrm{T}$ cells, to heat shock proteins of Francisella tularensis. Scand J Infect Dis 2001; 33:145-52.

49 Lee BY, Horwitz MA, Clemens DL. Identification, recombinant expression, immunolocalization in macrophages, and T-cell responsiveness of the major extracellular proteins of Francisella tularensis. Infect Immun 2006; 74:4002-13.

50 Noah CE, Malik M, Bublitz DC, Camenares D, Sellati TJ, Benach JL, Furie MB. GroEL and lipopolysaccharide from Francisella tularensis live vaccine strain synergistically activate human macrophages. Infect Immun 2010; 78:1797-806.

51 Asea A, Kabingu E, Stevenson MA, Calderwood SK. HSP70 peptide-bearing and peptide-negative preparations act as chaperokines. Cell Stress Chaperones 2000; 5:42531.

52 Quintana FJ, Cohen IR. Heat shock proteins as endogenous adjuvants in sterile and septic inflammation. J Immunol 2005; 175:2777-82.

53 Zugel U, Kaufmann SH. Role of heat shock proteins in protection from and pathogenesis of infectious diseases. Clin Microbiol Rev 1999; 12:19-39.

54 Nano FE, Schmerk C. The Francisella pathogenicity island. Ann N Y Acad Sci 2007; 1105:122-37.

55 Bonquist L, Lindgren H, Golovliov I, Guina T, Sjostedt A. MglA and Igl proteins contribute to the modulation of Francisella tularensis live vaccine strain-containing phagosomes in murine macrophages. Infect Immun 2008; 76:3502-10.

56 Nano FE, Zhang N, Cowley SC et al. A Francisella tularensis pathogenicity island required for intramacrophage growth. J Bacteriol 2004; 186:6430-6.

57 Cong Y, Yu JJ, Guentzel MN, Berton MT, Seshu J, Klose KE, Arulanandam BP. Vaccination with a defined Francisella tularensis subsp. novicida pathogenicity island mutan (DeltaiglB) induces protective immunity against homotypic and heterotypic challenge. Vaccine 2009; 27:5554-61
58 Gray CG, Cowley SC, Cheung KK, Nano FE. The identification of five genetic loci of Francisella novicida associated with intracellular growth. FEMS Microbiol Lett 2002; 215:53-6.

59 Kadzhaev K, Zingmark C, Golovliov I, Bolanowski M, Shen H, Conlan W, Sjostedt A. Identification of genes contributing to the virulence of Francisella tularensis SCHU S4 in a mouse intradermal infection model. PLoS ONE 2009; 4:e5463.

60 Su J, Yang J, Zhao D, Kawula TH, Banas JA, Zhang JR. Genome-wide identification of Francisella tularensis virulence determinants. Infect Immun 2007; 75:3089-101.

61 Wehrly TD, Chong A, Virtaneva $\mathrm{K}$ et al. Intracellular biology and virulence determinants of Francisella tularensis revealed by transcriptional profiling inside macrophages. Cell Microbiol 2009; 11:1128-50.

62 Broms JE, Lavander M, Sjostedt A. A conserved alpha-helix essential for a type VI secretion-like system of Francisella tularensis. J Bacteriol 2009; 191:2431-46.

63 de Bruin OM, Ludu JS, Nano FE. The Francisella pathogenicity island protein IglA localizes to the bacterial cytoplasm and is needed for intracellular growth. BMC Microbiol 2007; 7:1.

64 Ludu JS, de Bruin OM, Duplantis BN, Schmerk CL, Chou AY, Elkins KL, Nano FE. The Francisella pathogenicity island protein $\mathrm{PdpD}$ is required for full virulence and associates with homologues of the type VI secretion system. J Bacteriol 2008; 190:4584-95.

65 Mougous JD, Cuff ME, Raunser S et al. A virulence locus of Pseudomonas aeruginosa encodes a protein secretion apparatus. Science 2006; 312:1526-30.

66 Pukatzki S, Ma AT, Sturtevant D et al. Identification of a conserved bacterial protein secretion system in Vibrio cholerae using the Dictyostelium host model system. Proc Nat Acad Sci U S A 2006; 103:1528-33.

67 Barker JR, Chong A, Wehrly TD et al. The Francisella tularensis pathogenicity island encodes a secretion system that is required for phagosome escape and virulence. Mol Microbiol 2009; 74:1459-70.

68 Barker JR, Klose KE. Molecular and genetic basis of pathogenesis in Francisella tularensis. Ann N Y Acad Sci 2007; 1105:138-59.

69 Sercarz EE, Lehmann PV, Ametani A, Benichou G, Miller A, Moudgil K. Dominance and crypticity of T cell antigenic determinants. Annu Rev Immunol 1993; 11:729-66.

70 Sette A, Grey H, Oseroff C et al. Definition of epitopes and antigens recognized by vaccinia specific immune responses: their conservation in variola virus sequences, and use as a model system to study complex pathogens. Vaccine 2009; 27(Suppl. 6):G21-6.

71 Assarsson E, Sidney J, Oseroff C et al. A quantitative analysis of the variables affecting the repertoire of $\mathrm{T}$ cell specificities recognized after vaccinia virus infection. J Immunol 2007; 178:7890-901.

72 Jia Q, Lee BY, Clemens DL, Bowen RA, Horwitz MA. Recombinant attenuated Listeria monocytogenes vaccine expressing Francisella tularensis IglC induces protection in mice against aerosolized Type A F. tularensis. Vaccine 2009; 27:1216-29.

73 Wayne Conlan J, Oyston PC. Vaccines against Francisella tularensis. Ann N Y Acad Sci 2007; 1105:325-50.

74 Sette A, Peters B. Immune epitope mapping in the post-genomic era: lessons for vaccine development. Curr Opin Immunol 2007; 19:106-10.

75 Anthony DD, Lehmann PV. T-cell epitope mapping using the ELISPOT approach. Methods 2003; 29:260-9.

76 Bian H, Reidhaar-Olson JF, Hammer J. The use of bioinformatics for identifying class II-restricted T-cell epitopes. Methods 2003; 29:299-309.

77 Buus S, Claesson MH. Identifying multiple tumor-specific epitopes from large-scale screening for overexpressed mRNA. Curr Opin Immunol 2004; 16:137-42.

78 Gregory SH, Mott S, Phung J et al. Epitope-based vaccination against pneumonic tularemia. Vaccine 2009; 27:5299-306.

79 Hoffmeister B, Kiecker F, Tesfa L, Volk HD, Picker LJ, Kern F. Mapping T cell epitopes by flow cytometry. Methods 2003; 29:270-81.

80 Koelle DM. Expression cloning for the discovery of viral antigens and epitopes recognized by T cells. Methods 2003; 29:213-26.

81 Lemmel C, Stevanovic S. The use of HPLC-MS in T-cell epitope identification. Methods 2003; 29:248-59.

82 Martin W, Sbai H, De Groot AS. Bioinformatics tools for identifying class I-restricted epitopes. Methods 2003; 29:289-98.

83 McMurry JA, Gregory SH, Moise L, Rivera D, Buus S, De Groot AS. Diversity of Francisella tularensis Schu4 antigens recognized by $\mathrm{T}$ lymphocytes after natural infections in humans: identification of candidate epitopes for inclusion in a rationally designed tularemia vaccine. Vaccine 2007; 25:3179-91.

84 Reijonen $\mathrm{H}$, Kwok WW. Use of HLA class II tetramers in tracking antigen-specific T cells and mapping T-cell epitopes. Methods 2003; 29:282-8.

85 Sospedra M, Pinilla C, Martin R. Use of combinatorial peptide libraries for T-cell epitope mapping. Methods 2003; 29:236-47.

86 Wang RF. Identification of MHC class II-restricted tumor antigens recognized by CD4 ${ }^{+}$ T cells. Methods 2003; 29:227-35.

87 Nielsen M, Lund O, Buus S, Lundegaard C. MHC Class II epitope predictive algorithms. Immunology 2010; 130:319-28.

88 Boyton RJ, Altmann DM. Transgenic models of autoimmune disease. Clin Exp Immunol 2002; 127:4-11. 